\title{
Ecological and economic mechanism for the formation of environmental measures in the gas extraction constructions
}

\author{
Elena $V$. Voskresenskaya ${ }^{1, *}$, Lybov G. Vorona-Slivinskaya ${ }^{2}$, Vitaly Snetkov ${ }^{1}$, Anatolii \\ Ponomarenko ${ }^{1}$ \\ ${ }^{1}$ Peter the Great St.Petersburg Polytechnic University, Polytechnicheskaya str., 29, 195251, St. \\ Petersburg, Russia \\ ${ }^{2}$ Saint Petersburg State University of Architecture and Civil Engineering, 2nd Krasnoarmeyskaya str., \\ 4, 190005, St. Petersburg, Russia
}

\begin{abstract}
The disturbed balance of the "society-nature" system has led to the fact that the production of output usually involves environmental pollution. The reason is that most technological processes are far from perfect and involve formation of intermediate substances or end products that do not participate in further production process and consequently become waste. Therefore, the authors analyze the methodological approaches of integrated environmental and economic assessment of environment protection measures during the construction of gas industry facilities, which is a relevant issue in terms of ecology. The authors claim that the extraction of fuel and energy resources disrupt the biogeocoenosises' components during the survey, development and exploitation of deposits, leading to the manifestation of dangerous natural management processes and destruction of flora and fauna. Therefore, the environmental-economic mechanism for the formation of environmental measures during the construction of gas facilities should be improved within the framework of the strategy of sustainable economic development of society and ensuring its environmental safety. Analysis of methods for assessing the environmental and economic impact of gas industry enterprises on the environment has shown that enterprises need further instrumental and methodological improvement.
\end{abstract}

\section{Introduction}

The modern intensification of the development of the raw materials complex of the Russian economy is accompanied by the inefficient use of the natural resources potential, an increase in the release of industrial substances into the environment, which leads to the destruction of ecosystems. In some cases, the volume of such wastes has already exceeded the natural, due to biogeochemical circulation. New unknown biochemical compounds have appeared and appear in the flows of these substances, the consequences of their introduction for the biosphere and man are unknown. One of the largest environmental pollutants are

\footnotetext{
*Corresponding author: elenvoskr@mail.ru
} 
objects of the gas industry. As a result of their activity, harmful substances are released into the atmosphere, polluted wastewater is discharged into the hydrosphere, and land is contaminated with solid industrial waste.

This defines the main goals and objectives of the gas industry in the field of environmental preservation and the development of environmental measures: introduction of resource-saving and environmentally friendly technologies, organization of production processes in environmentally friendly setting, reclamation of disturbed and contaminated lands, etc. One of the basic principles for the future operation of gas industry facilities should be the approach of a systemic view of nature and production as a whole, consisting of environmental and social factors that will help to prevent the formation and increase in waste processing and, ultimately, reduce the anthropogenic influence to a level that does not adversely affect the natural environment. In this regard, the development of more sophisticated methodological approaches for the integrated environmental and economic assessment of environmental preservation measures in the construction and operation of gas industry facilities is highly relevant. Studies of many specialists are devoted to the issues of the ecological and economic mechanism for the formation of environmental measures during the construction of gas facilities. The most significant of those are the works: E. Syromyatnikov [1], Yu. Zemenkov [2], M. Ginzburg, L. Krasnova [3], I. Ivanov [4], M. Gureeva [5]. However, the scientific development of this problem is nowhere near exhausted, since the existing mechanism of environmental preservation activities in the construction of gas industry facilities does not fully ensure the rational combination of economic activities of industry enterprises based on market principles of the economy and the process of environmental protection and reproduction. The problems of interaction between the economic and environmental components of reproduction processes in various fields of the national economy are investigated in the works of the authors of this article: E. Voskresenskaya [68], L. Vorona-Slivinskaya [8, 10], V. Snetkov [6, 7].

\section{Materials and Methods}

The studies of Russian and foreign scientists in the field of ecology and environmental economics created the methodological and theoretical basis. These studies explain the general patterns of socio-economic and environmental policy in the fuel and energy complex, as well as the fundamental concepts and hypotheses of interaction between society and nature in the process of building gas facilities, modern mechanisms of market economy in the field of conservation and environmental management.

The information basis was dwelled on the materials of the Federal State Statistics Service of the Russian Federation, reporting materials of organizations of the gas industry, the Ministry of Natural Resources and Environment of the Russian Federation.

\section{Results}

The priority directions of environmental and economic substantiation of the state of the environment in the process of operation of gas industry facilities should be: determination of economic damage to components of biogeocoenosis with an account of the environmental situation in the region; determination of the economic effect as a result of reducing the area of disturbed lands, as well as reducing the risk of ecological accidents through the introduction of environmental actions, innovation, environmental and economic monitoring and environmental impact assessment at industry enterprises. In the last decade, a significant increase in investments in environmental measures has been observed in the gas industry, which, however, does not always lead to the expected effect due to the imperfection of the 
presented materials or incomplete consideration of certain environmental factors. Improving the efficiency of investments can be achieved by applying the author's model of planning and control of environmental activities in the development of the section "Environmental Protection" in the pre-project and project documentation.

\section{Discussion}

All economic activities are accompanied by the extraction of natural resources, which adversely affects the safety and productivity of the Earth's ecosystems. Important principles of environmental protection are: focus on the prevention of negative consequences from various impacts in the process of human activity, comprehensiveness, ubiquity, territorial differentiation and scientific ecological soundness. At present, the Russian economy is distinguished by exceptionally high environmental intensity, which is reflected in the enormous expenditure of natural resources to obtain the final economic results, in a significant level of specific pollution per unit of production. In the country as a whole, up to $70 \%$ of thermal pollution and about $50 \%$ of all harmful emissions fall on the energy sector, which facilities are not only the largest consumers of natural resources, but also significant sources of pollution of all elements of the environment. The main environmental problem to develop gas fields is dangerous geological processes: landslides, rock deformation, in some cases, the development of fields leads to the impoverishment or complete destruction of flora and fauna. Damage to the environment can also be caused by accidents of existing equipment, as well as deterioration of public health in the areas where enterprises operate.

Table 1 provides statistical information on the extraction and processing of the main types of minerals in Russia.

Table 1. Extraction and processing of major types of mineral resources.

\begin{tabular}{|c|c|c|}
\hline Index & 2016 & 2017 \\
\hline Hard coal and lignite coal, million tons & 385 & 410 \\
\hline Non-agglomerated peat, million tons & 1,2 & 0,9 \\
\hline Crude oil, including gas condensate, million tons & 548 & 546 \\
\hline Natural and associated gas, billion $\mathrm{m}^{3}$ & 640 & 691 \\
\hline Iron-ore concentrate, million tons & 101 & 95,0 \\
\hline Gold ores and concentrates, as \% of the previous year & 10,2 & 106,4 \\
\hline Natural sands, million $\mathrm{m}^{3}$ & 235 & 249 \\
\hline${\text { Granules, chipping and powder, pebbles, gravel, million } \mathrm{m}^{3}}^{2}$ & 254 & 265 \\
\hline
\end{tabular}

An annual increase in the extraction and processing of the main types of minerals is seen. Table 2 and 3 display the performance indicators of the gas industry (Russian Statistical Yearbook (2017)

Table 2. Gas production and processing, billion $\mathrm{m}^{3}$.

\begin{tabular}{|c|c|c|c|c|}
\hline Index & 2010 & 2014 & 2015 & 2016 \\
\hline $\begin{array}{c}\text { Natural and associated gas } \\
\text { including }\end{array}$ & 651 & 642 & 634 & 641 \\
\hline $\begin{array}{c}\text { combustible natural gas } \\
\text { associated petroleum gas (combustible } \\
\text { natural gas) of oil deposits }\end{array}$ & 593 & 569 & 555 & 557 \\
\hline Dry gas & 16.1 & 14.9 & 15.9 & 15.6 \\
\hline $\begin{array}{c}\text { Liquefied and regasified combustible } \\
\text { natural gas, min. tonnes }\end{array}$ & 10.0 & 10.7 & 10.8 & 10.9 \\
\hline
\end{tabular}


Table 3. Production and use of associated petroleum gas, billion $\mathrm{m}^{3}$.

\begin{tabular}{|l|r|r|r|r|}
\hline \multicolumn{1}{|c|}{ Index } & 2010 & 2014 & 2015 & 2016 \\
\hline Extraction & 49.3 & 64.3 & 68.4 & 70.8 \\
\hline Consumption for own needs & 8.0 & 14.4 & 14.9 & 14.7 \\
\hline $\begin{array}{l}\text { Technological losses during } \\
\text { cleaning, drying and transportation }\end{array}$ & 0.8 & 0.4 & 0.6 & 0.9 \\
\hline Flared & 15.0 & 10.9 & 9.7 & 9.7 \\
\hline
\end{tabular}

The study showed that a system of environmental measures has been developed and is being implemented in the gas industry, which makes it possible to increase the area of remediated lands, reduce emissions to the atmosphere and discharge of polluted wastewater. These measures are justified by the data of industrial environmental monitoring and are carried out due to the positive dynamics of capital investments of gas industry entities in environmental protection activities. Table 4 provides information on the commissioning of certain production facilities (Russian Statistical Yearbook (2017)

Table 4. Commissioning of production facilities.

\begin{tabular}{|c|c|c|c|c|}
\hline Index & 2010 & 2014 & 2015 & 2016 \\
\hline Capacities for mining and processing of: & & & & \\
\hline coal, min. tonnes & 8.2 & 5.4 & 4.6 & 4.5 \\
\hline crude oil, min. tonnes & 6.8 & 5.5 & 15.1 & 0.2 \\
\hline gas, bln. ${ }^{2}$ & $\ldots$ & 1.2 & 0.9 & 3.7 \\
\hline
\end{tabular}

The transition of Russia to a market economy was accompanied by high activity in the development of the gas industry, but the severity of the economic crisis overshadowed the awareness of the consequences of the environmental crisis, which came through the reduction of environmental quality and, as a result, through deterioration of health of the population, reducing life expectancy and other negative demographic consequences.

Thus, there is an urgent need to create a new state environmental policy aimed at ensuring sustainable environmental management. In 2016, the share of gas industry organizations that implemented technological innovations in the environmental field was $9.2 \%$, process innovations $-5.2 \%$, and product innovations $-5.5 \%$ of the total number of surveyed organizations.

The main objectives in the field of environmental protection in the gas industry remain the reduction of emissions and discharges of hazardous substances by energy enterprises, the prevention of the formation and increase of recycling of industrial waste, and the remediation of disturbed and contaminated lands. The rational direction of development of the industry and reduction of the negative impact of its facilities on the environment is the introduction and development of resource-saving and green technologies.

In accordance with the sectoral environmental program of the gas industry entities, the following priorities in the field of ecology preservation and rational environmental management should be highlighted: preservation of the natural environment in the area where gas facilities are located, rational use of natural resources; ensuring industrial and environmental safety of the construction and operation of gas production, processing, transportation and storage facilities; ensuring labor safety and preserving the health of workers in the industry; participation in ensuring the environmental safety of the regions in which the facilities of the subjects of the gas industry are located through organizational, technical and financial measures. 


\section{Conclusions}

Therefore, every investment project in the gas industry should be subject to environmental impact assessment, including monitoring the environmental impact of the project, determining environmental problems, adjusting measures and calculating their efficiency in preventing or reducing such impacts. The process of examination of a complex of environmental measures during the construction and operation of gas industry facilities should be automated and include the estimation of possible economic damage for the project elements, calculation of the efficiency of the complex of environmental measures, as well as prevented and residual losses, which allow to adjust a project at the pre-design stage.

The provision of land for the construction of gas pipelines has a number of features related to the preservation of soil fertility, flora and fauna in the adjacent territories. Compliance with environmental protection requirements necessitates the construction of additional engineering structures that contribute to the environmentally safe operation of gas pipelines, the remediation of disturbed lands, and compensation for losses to land owners, users and tenants in areas of agricultural production. The method of assessing damage from the destruction and irretrievable losses of agricultural land, based on the definition of natural and cost indicators, allows to determine the most balanced design solution in terms of environmental and economic parameters.

The ecological and economic mechanism for the formation of environmental measures during the construction of gas industry facilities involves the creation of a system of environmental restrictions aimed at the economical use of land resources, preventing pollution and disturbance of soil, that is based on the use of an assessment system for environmentally sound use of natural resources.

\section{References}

1. E. Syromyatnikov, Quality management in the oil and gas industry (2005)

2. Yu. Zemenkov, Operation of equipment and facilities of the gas industry (2017)

3. M. Ginzburg, L. Krasnova, Financial management at the enterprises of oil and gas industry (2016)

4. I. Ivanov, System analysis of geoecological risks in gas industry (2007)

5. M. Gureeva, Fundamentals of the economy of oil and gas industry (2007)

6. E. Voskresenskaya, V. Snetkov A. Tebryaev, Z. Askarov, V 2017 MATEC Web of Conferences 106, 08055 (2018)

7. E. Voskresenskaya, V. Snetkov, A. Tebryaev, V E3S Web of Conferences 33, 03051 (2018) doi.org/10.1051/e3sconf/20183303051

8. E. Voskresenskaya, L. Vorona-Slivinskaya, V E3S Web of Conferences 33, 03052 (2018) https://doi.org/10.1051/e3sconf/20183303052

9. E. Voskresenskaya, D. Mokhorov, A. Tebryaev, Matec web of conferences 170, 01058 (2018) DOI https://doi.org/10.1051/matecconf/201817001058

10. E. Voskresenskaya, N. Zhilskiy, E. Shariapova, Matec web of conferences 170, 01057 (2018) DOI https://doi.org/10.1051/matecconf/201817001057 